\title{
Online measurement of floc size, viscosity, and consistency of cellulose microfibril suspensions with optical coherence tomography
}

\author{
Janne Lauri · Sanna Haavisto · Juha Salmela • Arttu Miettinen • \\ Tapio Fabritius $\cdot$ Antti I. Koponen
}

Received: 22 October 2020/ Accepted: 3 February 2021 / Published online: 18 February 2021

(C) The Author(s) 2021

\begin{abstract}
In this study, cellulose microfibril (CMF) suspensions were imaged during pipe flow at consistencies of $0.4 \%, 1.0 \%$, and $1.6 \%$ with optical coherence tomography (OCT) to obtain images of the structure and the local velocity of the suspension. The viscosities obtained by combining pressure loss measurement with the OCT velocity data showed typical shear thinning behavior and were in excellent agreement with viscosities obtained with ultrasound velocity profiling. The structural OCT images were used to calculate the radial and the axial floc sizes of the suspension. A fit of power law to the geometrical floc size-shear stress data gave the same power law index for all consistencies, suggesting that floc rupture dynamics is independent of consistency. The
\end{abstract}

J. Lauri · T. Fabritius

Faculty of Information Technology and Electrical

Engineering, Optoelectronics and Measurement

Techniques Research Unit, University of Oulu,

P.O. Box 4500, 90014 Oulu, Finland

S. Haavisto · J. Salmela

Spinnova Ltd, Palokärjentie 2-4, 40320 Jyväskylä, Finland

A. Miettinen

Department of Physics, University of Jyväskylä,

P.O. Box 35, 40014 Jyväskylä, Finland

A. I. Koponen $(\bowtie)$

VTT Technical Research Centre of Finland Ltd,

P.O. Box 1603, 40101 Jyväskylä, Finland

e-mail: Antti.Koponen@vtt.fi dependence of viscosity and floc size on shear stress was similar, indicating that the shear thinning behavior of CMF suspensions is closely related to the rupture dynamics of flocs. The results also showed that an apparent attenuation coefficient of the OCT signal can be used to determine the consistency of $\mathrm{CMF}$ suspensions.

Keywords Cellulose microfibrils $\cdot \mathrm{CMF}$. Rheology · Viscosity · Flocculation · Floc size · Consistency · Optical coherence tomography · OCT

\section{Introduction}

Cellulose microfibrils (CMFs) are a sustainable and a biodegradable material that make it possible to develop novel, all-cellulose products due to, for instance, its lightness, mechanical robustness, and barrier properties (Klemm et al. 2011; Lavoine et al. 2012; Moon et al. 2016). CMFs are already being utilized in many applications, such as to reinforce paper and composite materials (Cheng et al. 2019; Eriksen et al. 2008; Lu et al. 2008), in various membranes and barrier films (Lavoine et al. 2012; Sharma et al. 2020), as a rheology modifier (DimicMisic et al. 2013; Li et al. 2015), and in energy-storage devices (Kim et al. 2019). CMFs are obtained from wood or plant cells through a chemical, enzymatic, or mechanical homogenization process (Desmaisons 
et al. 2017; Nechyporchuk et al. 2016). The cellulose fibers are at that point broken down into bundles of individual CMF fibrils. The size distribution of the fibrils obtained is broad and varies a great deal depending on the disintegration process. Typically, the fibrils exhibit diameters at a scale of tens of nanometers and length to diameter ratios (aspect ratios) in the hundreds. The specific surface area (and, thus, hydroxyl group surface density) is much higher for CMF fibrils than for regular cellulose fibers. For these reasons, CMFs easily form networks that are often encountered as flocs, gels, and films, and therefore, the gross structure of the CMF suspensions is much larger than the size of individual fibrils (Hubbe et al. 2017; Karppinen et al. 2012; Pääkkönen et al. 2016; Raj et al. 2017).

The raw CMF material is usually suspended in water before and during processing and production. Rheological characterization of the CMF suspensions is a widely discussed topic and is relevant from both practical and academic standpoints (Hubbe et al. 2017; Iotti et al. 2011; Kumar et al. 2016; Mohtaschemi et al. 2014c; Schenker et al. 2019; Tatsumi et al. 2002). Generally, CMF suspensions are shear-thinning power law fluids-their viscosity is, i.e., given with a good accuracy by the formula

$\mu=K \dot{\gamma}^{n-1}$,

where $\dot{\gamma}$ is the shear rate, $K$ is the consistency index, and $n<1$ is the flow index (Honorato et al. 2015; Lasseuguette et al. 2008; Mohtaschemi et al. 2014a; Dimic-Misic et al. 2013). The viscosity dependence of CMF suspensions on consistency is similar for different CMF grades (Koponen 2020). This similarity is likely due to the flow dynamics of CMF suspensions not being that of individual fibrils but of flocs dispersed in a liquid phase or in a gel-like matrix (Hubbe et al. 2017; Saarikoski et al. 2012).

Similarly to pulp fibres or particle suspensions in general (Barnes 1995, 2000), CMF suspensions have a strong tendency to apparent slip flow at solid walls (Hubbe et al. 2017; Kumar et al. 2016; Martoïa et al. 2015; Nechyporchuk et al. 2014; Saarikoski et al. 2012; Turpeinen et al. 2020). The apparent slip is caused by a wall depletion layer, where the consistency changes from a nearly fibril-free zone to bulk consistency (Kataja et al. 2017; Lauri et al. 2017; Saarinen et al. 2014). It should not be mixed with the slip of polymer melts where there can be an actual violation of the no-slip boundary condition (Brochard and De Gennes 1992). For simplicity, we will omit the term 'apparent' from slip below. The slip behavior between CMF grades can be quite different and often causes problems in rheometers by making it challenging to obtain reliable information about shear rheology (Haavisto et al. 2015; Schenker et al. 2018; Turpeinen et al. 2020; Vadodaria et al. 2018). In addition to slip behavior, sample preparation and shear history may also change the properties of the CMF and can make reliable and repeatable characterizations of them difficult (Liao et al. 2020; Naderi and Lindström 2015).

Dynamic flocculation and slip phenomena affect the rheological properties of suspensions in the processing industry and often dictate the product quality and properties, process performance, and economics (Raj et al. 2017). Therefore, accurate rheological measurements are essential when developing and manufacturing high-quality products with high repeatability. However, only a few studies to date have investigated the flocculation of CMF suspensions in dynamic flow conditions, and typically the analyses have been performed off-line in a laboratory, while it would be more beneficial to monitor the bulk properties of the CMF suspension, such as viscosity, floc size, and consistency, online in the actual process conditions. Pääkkönen et al. (2016) measured CMF floc size using the dynamic light scattering method (DLS) in stationary conditions with photon correlation spectroscopy. Saarikoski et al. (2012), Karppinen et al. (2012), Saarinen et al. (2014), and Martoïa et al. (2015) carried out CMF flocculation studies by combining a transparent cylindrical rotational rheometer with digital imaging. Raj et al. (2017) used focused beam reflectance measurement (FBRM) by immersing the probe in a stirred CMF suspension.

Due to the development of non-invasive flow measurement techniques, velocity profiling has become an important tool for online rheological analysis (Powell 2008). Here, the velocity profile of the studied fluid is measured in laminar flow conditions in a circular pipe in the radial direction. The viscosity at distance $z$ from the wall is then

$\mu(z)=\dot{\gamma}(z) / \tau(z)$,

where the local shear rate, $\dot{\gamma}(z)$, is obtained by 
differentiating the measured velocity profile, $v(z)$, and the shear stress distribution

$\tau(z)=\Delta P(R-z) / 2 \Delta l$

is determined from the simultaneously measured pressure drop $\Delta P$ over distance $\Delta l$ (here $R$ is the pipe radius). While magnetic resonance imaging (MRI) is also an option (Arola et al. 1997; Rofe et al. 1996), the most popular method for velocity profiling is ultrasound (UVP), which is widely used in various real-life industrial processes (Derakhshandeh et al. 2010; Takeda 2012; Wunderlich and Brunn 1999).

A promising higher-resolution alternative for structural imaging and velocity profiling is optical coherence tomography (OCT). Here, low-coherence, nearinfrared light is used to non-destructively probe the reflectivity and speed of the sample as a function of depth (Chen et al. 1997; Drexler and Fujimoto 2008; Huang et al. 1991). By acquiring multiple side-by-side depth profiles (A-scans), a tomographic image of both the structure and the flow field of the sample is obtained. The temporal resolution of OCT is relatively high-tens of thousands of depth profiles can be acquired per second using specific frequency-domain techniques. This makes it possible to acquire sharp images of relatively fast flowing suspensions. The resolution of the images is at the micrometer scale both axially and radially with respect to the probing light beam. The greatest downside of the OCT technique is that the sample must be semi-transparent to the probing light, and even then, the sensitivity of the measurement decreases rapidly with increasing depth. The achievable imaging depth depends strongly on the sample, with typical values being in the range of a few millimeters. Since the thickness of the walldepletion layer of CMF suspensions is typically rather small, the measurement range of OCT is usually high enough not only to analyze the wall-depletion layer but also the bulk behavior of the studied fluid (Kataja et al. 2017; Lauri et al. 2017). OCT has the advantage over digital imaging, DLS, and FBRM in online measurements due to the fact that it can see beyond the wall-depletion layer and it gives information on both the axial and the radial floc sizes. Moreover, unlike in digital imaging, the optical access window can be small and does not require immersion, like FBRM. Previously, Koponen et al. (2018) demonstrated the use of structural OCT images for analyzing CMF flocculation.

In this study, structural OCT data is used to analyze the flocculation behavior of an aqueous suspension of mechanically disintegrated cellulose microfibrils in a pipe flow at three different consistencies $(0.4 \%, 1.0 \%$, and $1.6 \%$ ). Moreover, the viscous behavior of the suspensions is determined from the OCT velocity profiles. Finally, the study will demonstrate that an apparent attenuation coefficient of the OCT signal can be used to determine the consistency of the CMF suspensions. The results demonstrate that while OCT is quite useful for academic CMF studies, it could also be used as a versatile quality and process control tool for $\mathrm{CMF}$ manufacturing and processing.

\section{Materials and methods}

\section{Cellulose microfibrils}

The CMFs used in this study are manufactured mechanically from purified wood pulp (Celish ${ }^{\circledR} \mathrm{KY}$ 100G, Daicel Chemical Industries, Japan). A polarized light microscope image and SEM image of the CMF are shown in Figs. 1a, b, respectively. The size distribution of the CMFs is quite wide, making it difficult to accurately and uniquely measure them. Tatsumi et al. (2002) reported an average length and diameter of $350 \mu \mathrm{m}$ and $15 \mu \mathrm{m}$, respectively, for the fibrils, while Kose et al. (2015) obtained an average fibril width of $0.7 \mu \mathrm{m}$. Varanasi et al. (2013) analyzed a fine mass fraction of the CMFs and estimated their average width and length to be $70 \mathrm{~nm}$ and $9 \mu \mathrm{m}$, respectively. (Notice that the CMF batches used in these studies have been similar; according to Daicel Chemical Industries the manufacturing process of Celish ${ }^{\circledR}$ KY-100G has remained the same during the years.) For the flow experiments, the original CMF suspension was diluted by tap water ${ }^{1}$ to mass consistencies of $0.4 \%, 1.0 \%$, and $1.6 \%$.

\footnotetext{
${ }^{1}$ The tap water at UC Davis, where the experiments were performed, is very hard-salinity is on the average $300 \mathrm{mg} / \mathrm{l}$ (City of Davis Public Works 2015).
} 

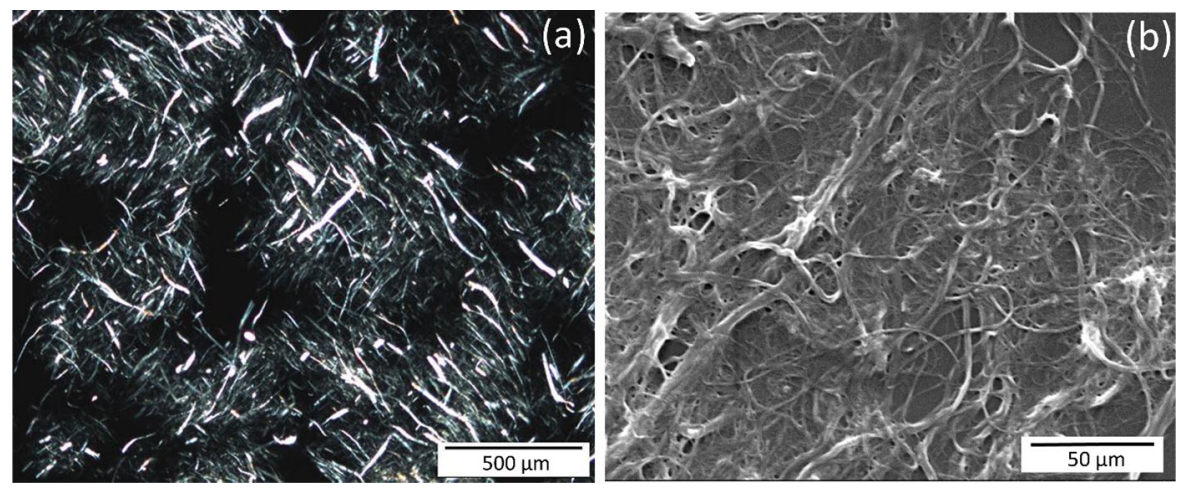

Fig. 1 A polarized light microscope image (a) and SEM image (b) of the CMFs (Haavisto et al. 2011)

\section{Experimental setup}

The measurement unit consisted of a $2.5 \mathrm{~m}$ long, optical-grade glass pipe with an inner diameter of $D=19 \mathrm{~mm}$ (Fig. 2a). Stable flow conditions in the pipe were induced by a low-pulsation, progressive cavity pump (Seepex MD series). The volume of the sample fluid in the loop, including the tank, was 13.51. The fluid temperature in the loop was set as $21{ }^{\circ} \mathrm{C}$ with a digital temperature controller (Model 9610, PolyScience). The volumetric flow rate in the loop was measured using a magnetic flow rate sensor (Sitrans F $\mathrm{M}$ MAGFLO). The measurements were conducted under stationary flow conditions at the flow rate range of $8 \mathrm{ml} / \mathrm{s}-169 \mathrm{ml} / \mathrm{s}$. To determine the wall shear stress at each flow rate, pressure drop was measured using a differential pressure sensor along the distance of $\Delta l=1.0 \mathrm{~m}$. In addition to the OCT device, the setup included an ultrasound velocity profiling (UVP) unit (DOP2000, Signal-Processing S.A., Switzerland), measurements reported previously by Kataja et al. (2017) and Koponen et al. (2019). The measurement setup has been explained in more detail by Haavisto et al. (2017).

Optical coherence tomography measurements

A commercial spectral domain OCT device (Telesto I SD-OCT, Thorlabs Inc.), operating at a $1325 \mathrm{~nm}$ center wavelength, was used to structural characterization and viscosity determination of the flowing CMF suspensions. The system has an inherent depth (radial direction, along the probing beam) resolution of approximately $7.5 \mu \mathrm{m}$ in air and approximately $5.6 \mu \mathrm{m}$ in water. The lateral (axial direction) resolution is approximately $15 \mu \mathrm{m}$. The maximum imaging depth range in air is $2.5 \mathrm{~mm}$, with the A-scan consisting of 512 pixels; thus, the pixel resolution in air is approximately $4.9 \mu \mathrm{m}$.

The OCT device was set up to perform continuous A-scans through the pipe wall and the suspension, such that the OCT probing beam remained in the same location all the time. The floc structure of the CMF suspension flowing past the OCT probing beam, and its local velocity, was captured in the resulting OCT images. The axial pixel size of the captured data depends on the local flow velocity and the A-scan rate of the OCT device.

The A-scan rate was set between 28 and $91 \mathrm{kHz}$, depending on the flow rate, to avoid phase wrapping in the velocity measurements (Xia et al. 2017). The angle between the OCT probing beam and the flow direction (Doppler angle), used to calculate the axial velocities (Haavisto et al. 2017), was $86.5^{\circ} \pm 0.2^{\circ}$, as determined from B-scan images composed of 4096 A-scans in a lateral range of $5.00 \mathrm{~mm}$.

Floc size analysis

The floc sizes were determined in the radial (normal to pipe wall) and the axial (along the pipe) directions. The floc size analysis was performed outside the wall depletion layer in the bulk region (see Fig. 2b), where the velocity profile is approximately linear and relatively shallow and the consistency is approximately constant. In the wall depletion region, consistency is an unknown function of the distance from the wall, whereas the steep velocity profile hinders simultaneous determination of the radial floc size and the velocity scaling of the axial floc size. For these 
(a)

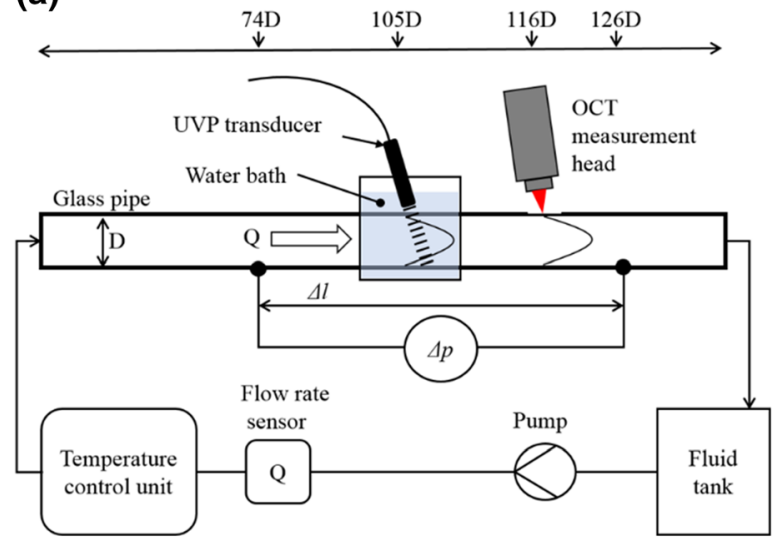

Fig. 2 a The measurement configuration. The suspension is pumped from the fluid tank to the pipe, which includes the flow rate sensor and the temperature control unit. OCT measurements are performed in the loop section, which consists of a glass pipe. The setup also included an ultrasound velocity profiling (UVP)

reasons, floc analysis would not be reasonable there. The distances from the wall where the bulk region begins were estimated from the onset of the linear part of the flow velocity profile: $150 \mu \mathrm{m}$ for $0.4 \%$ (see Fig. 2b), $100 \mu \mathrm{m}$ for $1.0 \%$, and $50 \mu \mathrm{m}$ for $1.6 \%$ consistencies. Also, the maximum imaging depth was estimated based on the velocity profile as the point where it began to deviate from the assumed linear profile in the bulk region due to attenuation of the optical signal and decreased signal-to-noise ratio (SNR). The maximum imaging depths were $670 \mu \mathrm{m}$ for $0.4 \%, 650 \mu \mathrm{m}$ for $1.0 \%$ and $520 \mu \mathrm{m}$ for $1.6 \%$ consistencies.

The floc size analysis followed for the most part the method introduced by Koponen et al. (2018). Initially, the depth-dependent decay of the OCT signal must be corrected. The decay is mainly caused by scattering and absorption of photons, fringe washout due to flowing scatterers (Yun et al. 2004), and inherent sensitivity decay of the system due to the finite pixel size of the spectrometer (Leitgeb et al. 2003). The depth-dependent decay was corrected by first calculating the average OCT signal as a function of depth and then scaling the pixel values at a given depth using the inverse of the average. This process ensures that the average OCT signal is equal in the corrected image at each depth.

To reduce granularity in the images, and to account for the different radial and axial resolutions of the OCT setup, the frames were resized to $11 \mu \mathrm{m} \times 11$

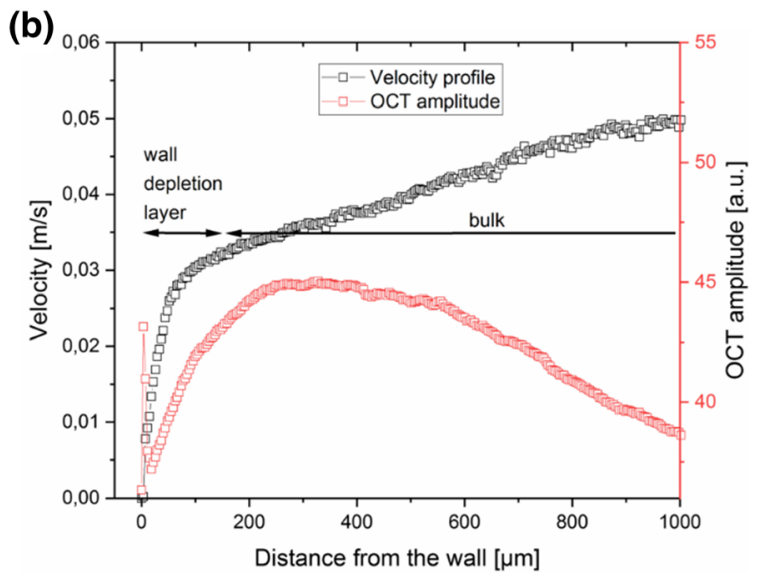

unit. b An example of the averaged velocity profile and the corresponding backscattering amplitude from the OCT measurements. The consistency is $0.4 \%$ and the flow rate is $24.7 \mathrm{ml} /$ $\mathrm{s}$

$\mu \mathrm{m}$ pixels. The native radial pixel size of $4.9 \mu \mathrm{m}$ (in air), the refractive index of water $(n=1.33)$, and the average axial velocity in the bulk region were taken into account in the scaling process. Unfortunately, the OCT velocity data used to calculate the flow velocity profile and the average axial velocity in the bulk region was only available as a separate set of measurements for a reduced number of flow rates. The average velocities in the floc measurement region, obtained from the available velocity profiles when plotted as a function of the flow rate, exhibited piecewise linear behavior, probably due to the combined effect of apparent wall slip and shear thinning. The velocities were fitted with piecewise linear functions $(1,2$, and 3 line segments for $0.4 \%, 1.0 \%$, and $1.6 \%$ consistencies, respectively) and interpolation was used to estimate the average axial velocities for all the flow rates. Figure 3 shows the average velocity as a function of flow rate for a $1.0 \% \mathrm{CMF}$ suspension together with the fitted interpolation function. For improved axial scaling accuracy, both structural and velocity data should be recorded for all the measurements. However, an error in the axial scaling mostly affects the determined floc size, while the trend remains undisturbed.

To determine the floc sizes, the resized images were thresholded using Otsu's method (N. Otsu 1979) instead of the median used by Koponen et al. (2018). The median thresholding assumes that half of the image consists of flocs and the other half of water. 


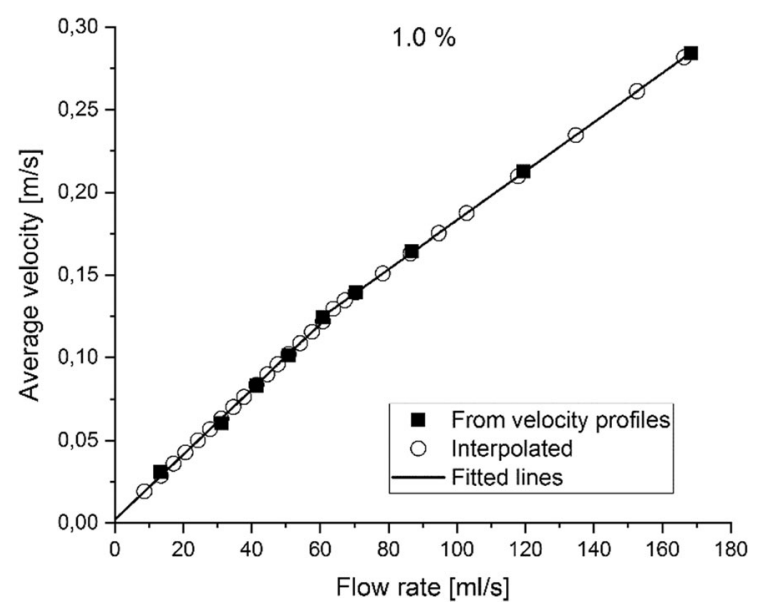

Fig. 3 Average velocity beyond but close to the wall-depletion layer in the bulk region for $1.0 \%$ consistency. The black rectangles are from the measured OCT velocity data and the solid lines represent the fitted piecewise linear function. The open circles (only structural data available, flow rate measured) are interpolated from the fits and used to scale the axial dimension in the floc size analysis

Such an assumption can lead to under- or overestimation of the area covered by the flocs, and furthermore, it can break down the flocs at high consistencies and combine them at low consistencies. Figure 4 shows resized images (upper row) and Otsu-thresholded images (lower row) for all the consistencies at the same flow rate of approximately $31 \mathrm{ml} / \mathrm{s}$.

The radial and axial floc size distributions were calculated as run-length distributions, in which the run-lengths are the lengths of the longest possible continuous line segments that are completely inside the CMF phase and oriented in the radial and axial directions, respectively. The obtained distribution histogram of run-lengths was weighted by the length and normalized by a sum of length counts. Images were acquired at two different OCT A-scan acquisition rates, $28 \mathrm{kHz}$ and $91 \mathrm{kHz}$. The SNR is reduced at the $91 \mathrm{kHz}$ A-scan rate compared to the $28 \mathrm{kHz}$ rate. This will cause discrepancies in thresholding and further in the floc sizes determined from the thresholded images. The discrepancy exhibits itself as an offset in the floc size values between the two A-scan acquisition rates, and it was compensated for by scaling the floc sizes acquired at $91 \mathrm{kHz}$, such that the floc size is approximately continuous as a function of wall shear stress (see Fig. 5).

\section{Results and discussion}

Viscosity and apparent shear banding

Figure 6 shows the measured pressure loss in the pipe as a function of the mean velocity. The shape of the curves resembles that of shear thinning fluids. Notice, however, that the wall slip makes the behavior more complex, as the increasing wall depletion with increasing wall shear stress may lead to apparent shear thinning (Kataja et al. 2017). Local viscosity of the CMF suspension above the wall-depletion layer can be directly calculated from Eq. (2) by utilizing the wall shear stress (obtained from the measured pressure loss) and the shear rate calculated from the OCT velocity profile, as explained in the Introduction. Since the velocity profile above the wall-depletion layer is locally approximately linear, the shear rates can be determined by fitting a line on the linear part of the

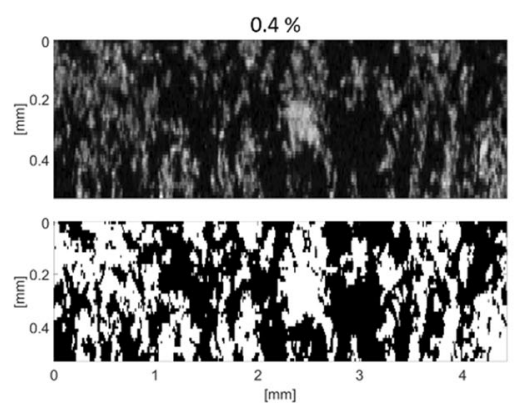

(a)

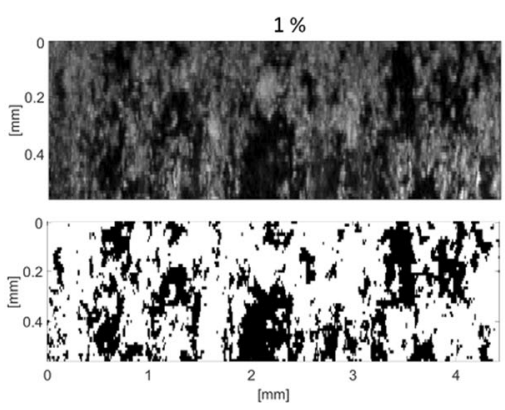

(b)

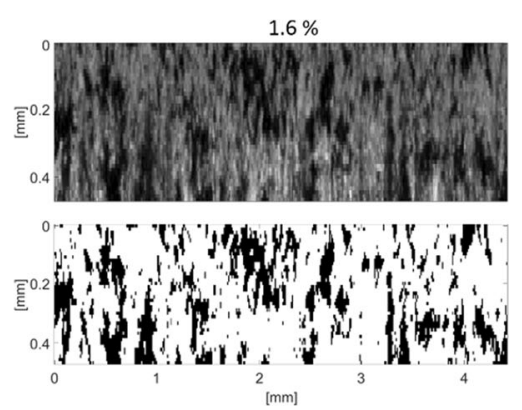

(c)
Fig. 4 Resized images with a uniform pixel size of $11 \mu \mathrm{m}$ (upper row) and corresponding Otsu-thresholded images (bottom row) for a $0.4 \%$, b $1.0 \%$, and c $1.6 \%$ consistencies. The white color depicts the fibrils and the black corresponds to water. The direction of the flow is from right to left, and only the bulk region is shown 


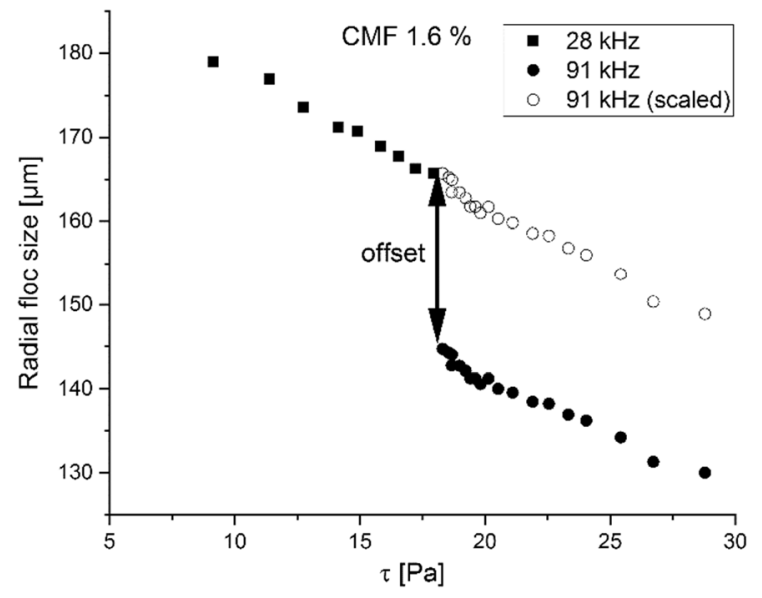

Fig. 5 The offset between the $28 \mathrm{kHz}$ and $91 \mathrm{kHz}$ scan rates. The offset is compensated for by a scaling factor that makes the floc size approximately continuous between the scan rates

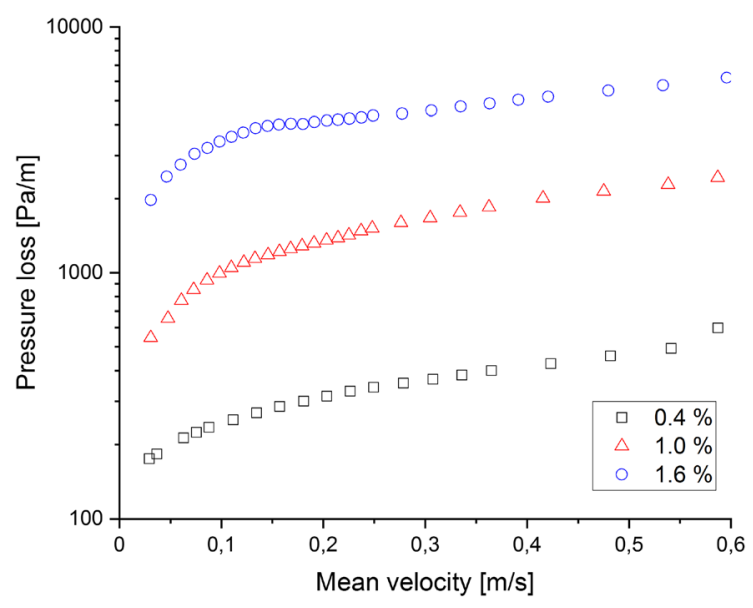

Fig. 6 Pressure loss as a function of the mean velocity in the whole pipe

measured velocity profile (see the solid lines in Fig. 7). The dashed lines in Fig. 7 are extensions of the linear fits. The fits are located at different distances from the wall. At a consistency of $1.6 \%$, the signal began to slightly decrease after a $300 \mu \mathrm{m}$ distance from the wall and was more evident after $500 \mu \mathrm{m}$. This was due to strong scattering and attenuation of the signal, which led to low SNR and unreliable determination of the velocity. Interestingly, at consistencies of $0.4 \%$ and $1.0 \%$ the velocity profiles differed from the linear fits at the beginning of the bulk region, which can clearly be seen from the extensions of the fitted lines (dashed lines). Such a behavior, which was consistently observed with all flow rates, could be due

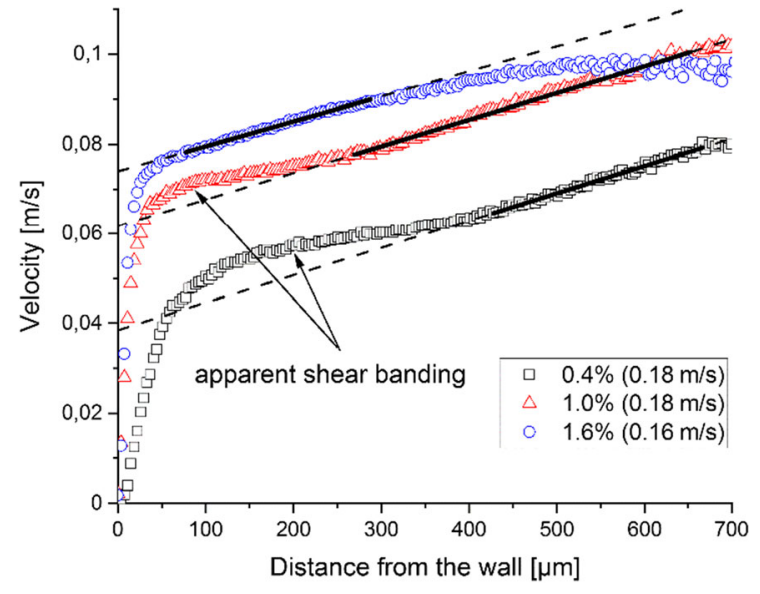

Fig. 7 Flow velocity profiles at a similar mean velocity. The solid lines depict linear fitted lines, while the dashed lines are extensions of the fits. There is apparent shear banding at consistencies of $0.4 \%$ and $1.0 \%$, which is probably caused by increased consistency in this region

to a shear banding process, in which a suspension has localized bands with different viscosities, and thus, shear rates due to a difference in the CMF structure, for instance in the fibril orientation or flocculation (Nechyporchuk et al. 2016). However, it is more likely that the CMF consistency was slightly higher in this region than in the interior parts of the pipe due to wall depletion, which pushed fibrils and flocs away from the wall. This finding is substantiated by the fact that the effect was stronger at lower consistencies, which also have a thicker wall-depletion layer (Koponen et al. 2019). At a consistency of $1.6 \%$, due to the more crowded suspension, the migration of individual fibrils and flocs away from the wall is not as easy as with lower consistencies. Here collective compression of the suspension may be an important mechanism in the creation of the depletion layer which could explain why protuberance was not seen in the velocity profile.

Figure 8 shows the viscosity calculated from Eq. (2) as a function of shear rate obtained from the straight solid lines shown in Fig. 7. The solid lines show viscosities for the same CMFs determined with the UVP method in the whole pipe (Koponen et al. 2019). The OCT viscosities corresponded well with the UVP data. Thus, the actual viscous behavior of the CMF suspensions can be obtained accurately with OCT in the vicinity of the pipe wall.

For estimating yield stress, $\tau_{y}$, the fit of the Herschel-Bulkley model $\tau=\tau_{y}+K \dot{\gamma}^{n}$ with the shear 


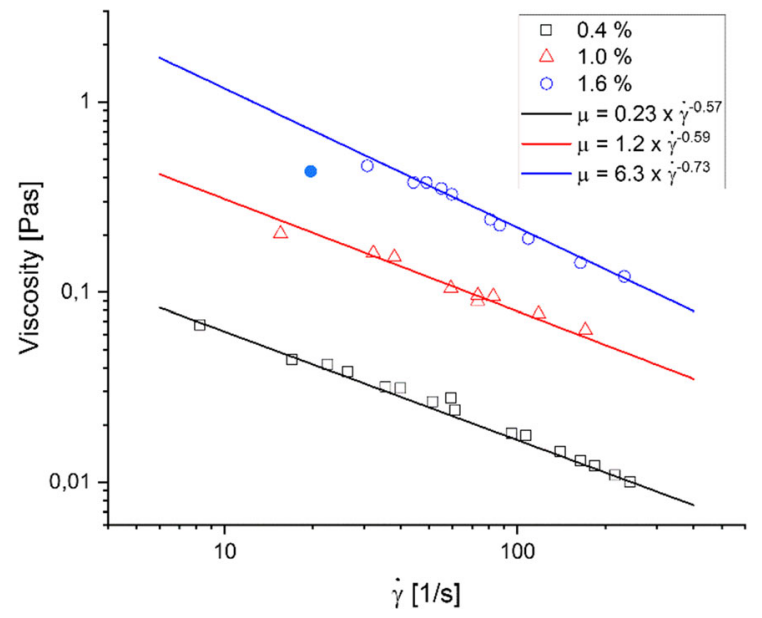

Fig. 8 Viscosity as a function of the shear rate. The solid lines show the viscous behavior obtained with UVP measurements for the same CMFs (Koponen et al. 2019). At a consistency of $1.6 \%$, the filled data point is close to the yield stress. Here large variation in the measured viscosity can occur, and thus, it deviates from the general trend

stress-shear rate data failed, and the yield stress was estimated using the Casson model $\tau^{0.5}=\tau_{\mathrm{y}}^{0.5}+a \gamma^{0.5}$ (Barnes et al. 1989). The obtained values for the yield stress were $0.5 \mathrm{~Pa}, 2 \mathrm{~Pa}$, and $9 \mathrm{~Pa}$, for $0.4 \%, 1.0 \%$ and $1.6 \%$ consistencies, respectively. Yield stress is here (just like the viscosity) smaller than in (Turpeinen et al. 2020); likely due to small differences in the used Celish batches and the different chemical composition of the used water (tap water vs. deionized water). Note that for the lowest shear rate, where the shear stress was $8.5 \mathrm{~Pa}$, i.e. slightly below the estimated yield stress, the viscosity of the $1.6 \%$ consistency differed clearly from the general trend (see the filled data point in Fig. 8). Here, the fluctuations around the yield point through continuous break-up and recovery of the network structure combined with a limited measurement time led to large variations in the measured viscosity (Lauri et al. 2017). We have omitted this data point in Fig. 11.

Floc size

Figure 9 shows the radial and the axial floc size distributions, which exhibit a roughly log-normal shape common to fibers and fibrils (Hourani 1988a, b; Koponen et al. 2018; Saarikoski et al. 2012) and many other flocculating particles (Coufort et al. 2008; Shin et al. 2015). At a consistency of 1.6\%, and to some extent also at $1.0 \%$, the measurement range was too short in the radial direction, which can be noted in the peaks at the highest floc size bins (see Fig. 9c, e). In the axial direction, the acquired image length was much longer, and therefore, we obtained undistorted distribution profiles. However, in order to evaluate and compare floc sizes, we limited the axial distributions to the same length as the radial distributions. For the average (length-weighted) floc size calculations, we omitted the peaks at the largest sizes and only used distributions up to the $450 \mu \mathrm{m}$ for all the cases. Note that most CMF grades are finer than the CMF used here. Thus, their floc size is generally smaller and complete floc size distributions would be obtained.

Figure 10a shows the average axial and radial floc sizes as a function of shear stress. The floc size was systematically smaller in the radial direction when compared to the axial direction. This was the case also in a study by Koponen et al. (2018) of a finer, mechanically disintegrated CMF at a $0.5 \%$ consistency. The likely reason for this occurrence is that the laminar pipe flow does not experience elongational (axial) stresses and the flocs are mainly broken by radial shear stress. This could also explain why the radial floc size decreased monotonically with increasing shear stress at all three consistencies, while the axial floc size at a consistency of $0.4 \%$ remained almost constant and the floc sizes at consistencies of $1.0 \%$ and $1.6 \%$ began decreasing monotonically only when a certain shear stress level was exceeded.

Figure 10b shows the geometric floc size, defined as a square root of the product of the axial and radial floc sizes as a function of shear stress. The straight lines are power law fits $L=G \tau^{-\beta}$ to the data, where $G$ and $\beta$ are the fitting parameters. The red markers show data points that have been omitted from the fits (two outliers at a consistency of $0.4 \%$, and the lowest shear stresses at consistencies of $1.0 \%$ and $1.6 \%$ ). We can see that the power law index, $\beta=-0.18$, was the same for all three consistencies. Thus, the floc rupture dynamics was independent of consistency with higher shear stresses. Finally, note that the floc size of $0.4 \%$ CMFs appeared to saturate at the highest shear stresses, but the number of data points was too small to draw any real conclusions.

The shear thinning behavior of CMF suspensions has been associated with decreasing floc size at an 

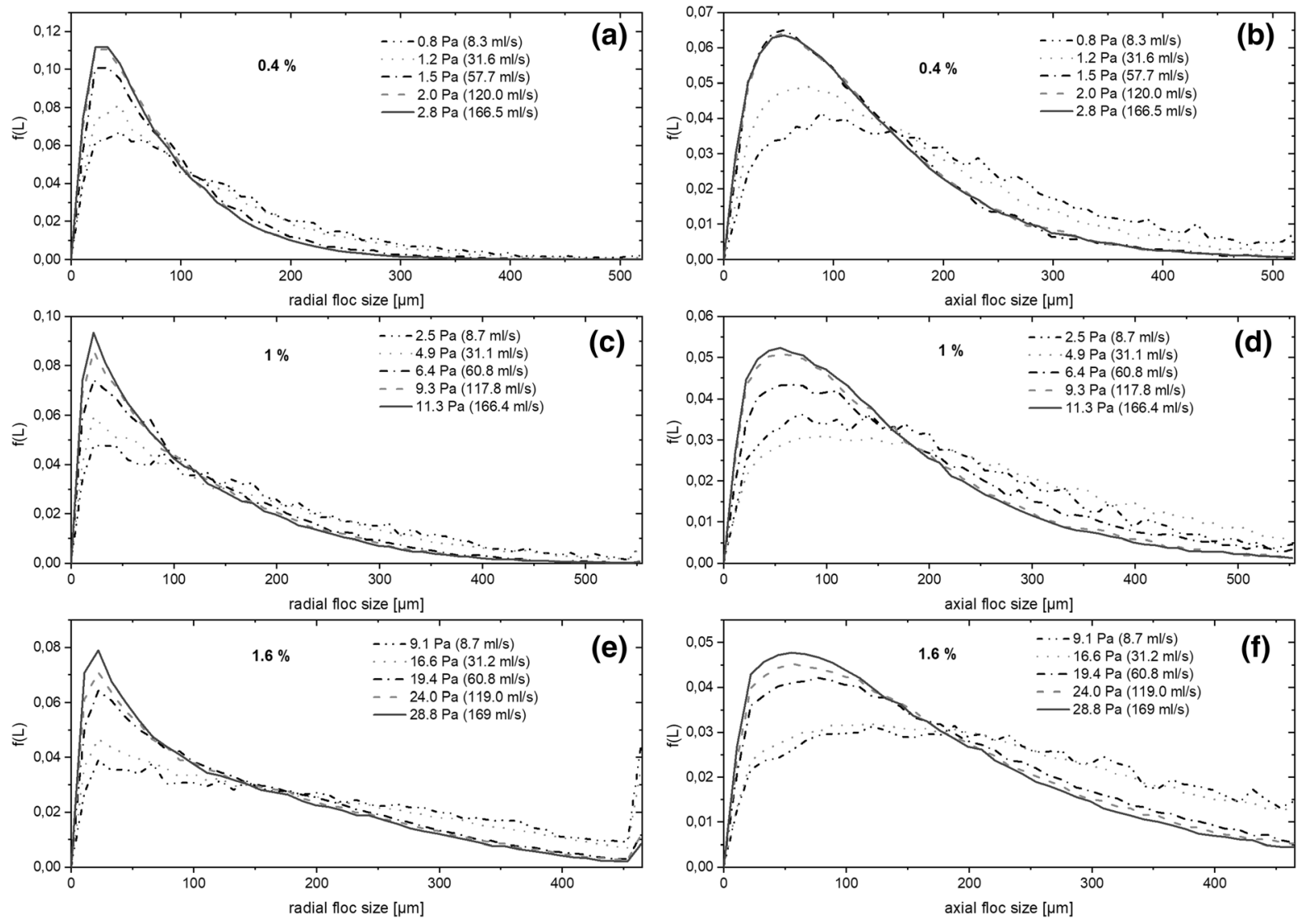

Fig. 9 Floc size distributions in the radial direction at consistencies of a $0.4 \%$, c $1.0 \%$, and e $1.6 \%$. Floc size d $1.0 \%$, and $\mathbf{f} 1.6 \%$. The numbers in the legend show the wall shear stress and the flow rate in the pipe distributions in the axial direction at consistencies of $\mathbf{b} 0.4 \%$,

(a)

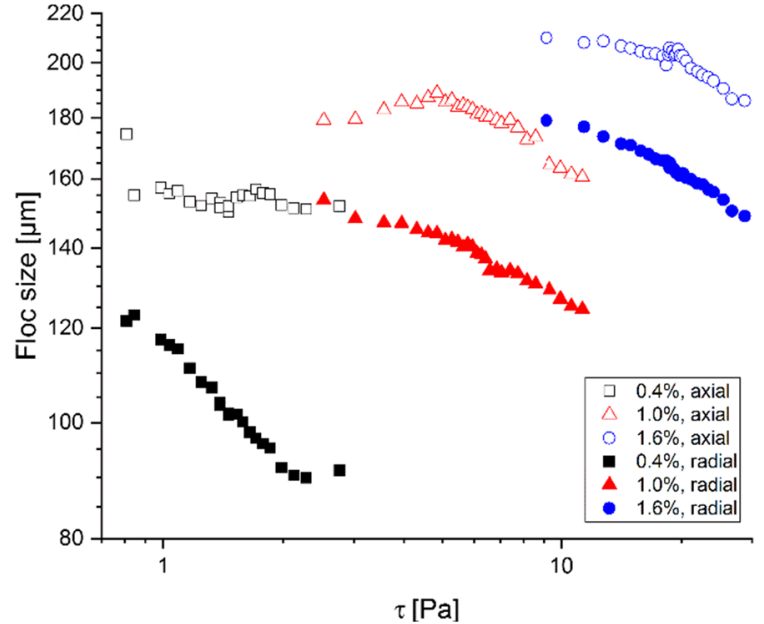

(b)

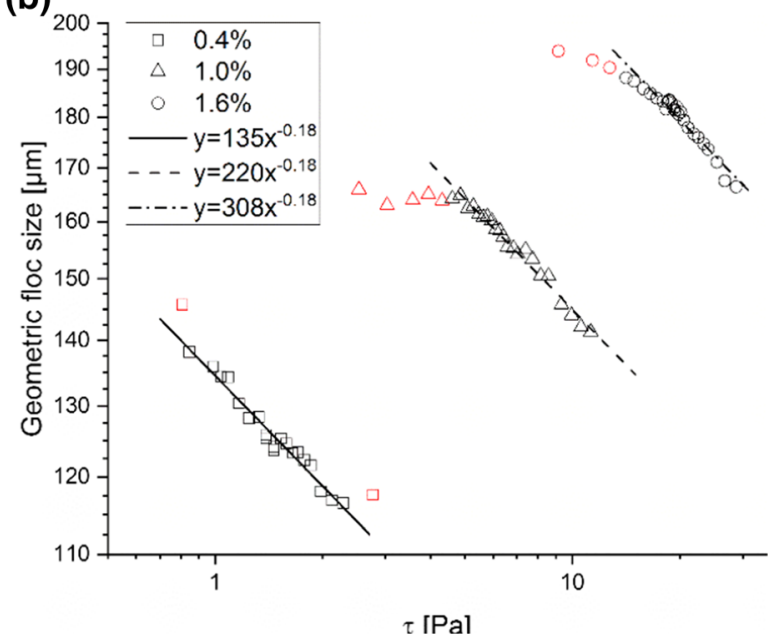

Fig. 10 a Radial and axial floc sizes as a function of shear stress. b Geometric floc sizes as a function of shear stress. The lines show power law fits to the measurement points shown with black markers 
increasing shear rate or shear stress (Mohtaschemi et al. 2014b; Puisto et al. 2012a, b). However, there is a lack of experimental data to support this assumption. Figure 11 shows the viscosity and the geometric floc size as a function of shear stress. We can see that there is a clear similarity between the floc size and the viscosity. To our knowledge, this data is the most direct evidence to date of the relationship between the CMF suspension viscosity and floc size. Note that while a power law gives a good approximation of the viscous behavior of the CMFs (see Fig. 8), the viscous behavior is in reality more complex. At a consistency of $1.0 \%$, and especially $1.6 \%$, the viscosity-shear stress data consist of two groups separated by a transition region. Similar viscosity behavior has also been noted by Lauri et al. (2017) for a finer CMF at a $0.5 \%$ consistency. The most obvious reason for such an abrupt change in the rheological behavior of the CMF suspension would be a sudden structural change in the suspension, for example in the fibril orientation (Mykhaylyk et al. 2016) and/or flocculation (Bounoua et al. 2016). Indeed, the floc size at a consistency of $1.0 \%$ follows rather consistently the viscosity behavior. However, at a consistency of $1.6 \%$ the floc size cannot explain the abrupt drop in viscosity at the shear stress of $20 \mathrm{~Pa}$. The changes in the floc aspect ratio (data not shown) were also too small to explain the observed behavior. It is possible that, for instance, concentration variations in the measurement region due to the wall depletion and subsequent compression of the $1.6 \%$ CMFs caused this to occur, but a clear

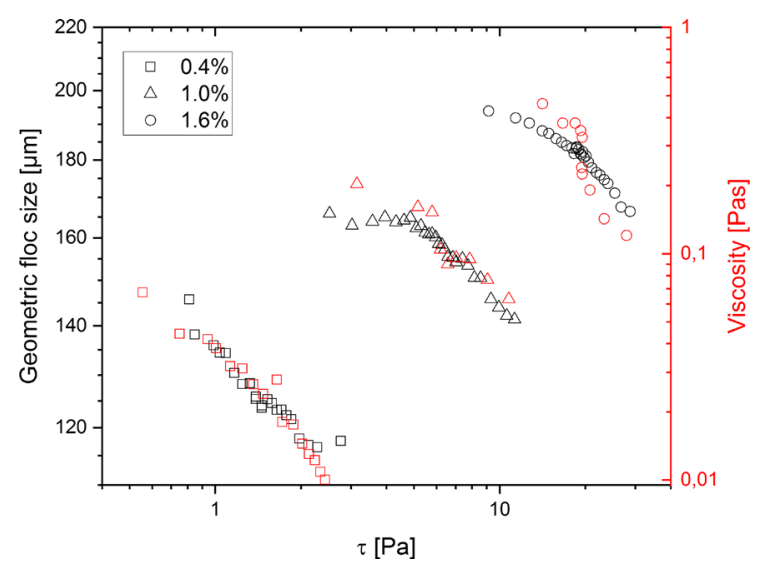

Fig. 11 Geometric floc size and viscosity as a function of the shear stress (log-log scale) explanation for the observed viscous behavior is currently lacking.

Consistency and OCT attenuation coefficient

The change in the consistency can be qualitatively estimated based on the OCT amplitude signal. A quantitative analysis is possible by utilizing an attenuation coefficient, the slope of the decaying signal (Gong et al. 2020; Vermeer et al. 2013), and predefined suspension consistencies for calibration. Multiple different factors in a measured sample influence the amplitude of an OCT signal. A large difference in refractive indexes between a scatterer and surrounding media increases the reflectivity and leads to a higher signal amplitude. In addition, higher particle concentration or, in this case, higher fibril consistency results in increased signal amplitude. On the other hand, a dense packing of scatterers can lead to dependent scattering, which will decrease the backscattered light intensity, and thus, the signal amplitude (Almasian et al. 2015; Kalkman et al. 2010). Other influencing factors, in addition to those already mentioned in the Materials and methods section, include particle size, the scattering anisotropy of the suspension, multiple scattering, and the depth of field of the focusing optics (Almasian et al. 2015; Kholodnykh et al. 2003; Thrane et al. 2000; Yadlowsky et al. 1995). There have been studies to estimate the concentration of spherical particles in static (Hillman et al. 2006; Sugita et al. 2016) and flow (Wang and Wang 2011) conditions via statistical analyses of the OCT amplitude signal. Such studies typically used homogenous suspension with monodispersed particle size; however, due to the complex size and shape distribution of CMFs, the direct applicability of the proposed theoretical formalisms should first be verified with simulations.

Decay of the OCT signal can be used to estimate an attenuation coefficient, which includes the effects of both scattering and absorption. It has been demonstrated that in the single scattering regime, the OCT intensity signal can be estimated by a Beer's law using a single exponential decay function

$I(z)=I_{0} e^{-2 u_{t} z}$,

where $z$ is the depth coordinate, $I_{0}$ is the incident intensity, and $u_{t}$ is the attenuation coefficient (Faber et al. 2004; Schmitt et al. 1993; Smithies et al. 1998). 
A factor of two in the exponent accounts for the roundtrip attenuation. In the present study, an apparent attenuation coefficient was determined by fitting the single exponential function with two variables (attenuation and intensity) to the linear part (in a log scale) of the OCT intensity signal (see Fig. 12a). Due to nonhomogeneous suspension, the fitting was performed at the highest flow rates to ensure reasonable sample length, and thus, good averaging of the data. A linear relationship of the obtained apparent attenuation coefficients and the CMF consistency is shown in Fig. 12b. The term "apparent" is used here because the sensitivity decay of the OCT system was not considered in the calculation and the absolute intensity values are not known. Due to the unknown intensity range of the OCT signal, the absolute coefficient values are only relative. However, they are expected to be at the upper limit, and the actual attenuation coefficients would then be smaller. This is because the single scattering approximation and the linear relationship between the attenuation coefficient and the consistency typically applies only in the weakly scattering regime, $u_{t}<5-10 \mathrm{~mm}^{-1}$ (Almasian et al. 2015; Faber et al. 2004; Kalkman et al. 2010). Nevertheless, the relative scattering coefficients are sufficient for monitoring consistency at the online conditions since the calibration slope (Fig. 12b) must always be determined in advance for each $\mathrm{CMF}$ suspension.

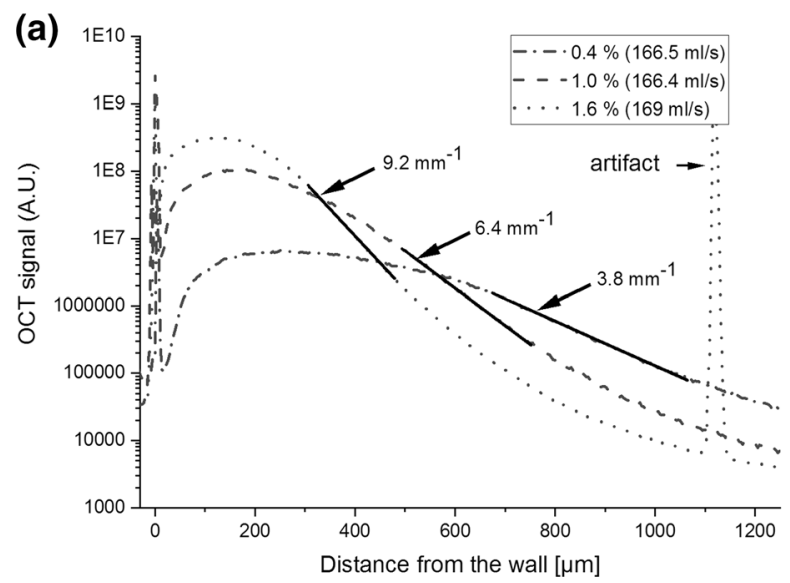

Fig. 12 a OCT signal measured at consistencies $0.4 \%, 1 \%$, and $1.6 \%$ (the solid lines are the fitted exponentials, $I(\mathrm{z})=A \mathrm{e}^{-2 B z}$, in which $A$ and $B$ are the fitting parameters). b The apparent

\section{Conclusions}

In this work, we applied OCT to analyze the viscous and structural properties of CMF suspensions at consistencies of $0.4 \%, 1.0 \%$, and $1.6 \%$. The measured viscosities agreed quite well with ultrasound velocity profiling performed for the same CMFs. Interestingly, the measured velocity profiles of the $0.4 \%$ and $1.0 \%$ CMFs showed apparent shear banding just above the wall depletion layer, which was manifested as a protuberance deviating from the generally linear velocity profile. This was probably caused by wall depletion, which pushed fibrils and flocs away from the wall, thereby increasing the local consistency of the suspension.

The structural OCT images were used to calculate the radial and axial floc sizes of the suspension. Floc size was systematically smaller in the radial direction than in the axial direction, most likely because the laminar pipe flow did not exhibit elongational (axial) stresses and the flocs were mainly broken by radial shear stress. A fit of a power law to geometrical floc size-shear stress data gave the same power law index for all consistencies. This suggests that floc rupture dynamics is independent of consistency. Comparison of the dependence of viscosity and floc size as a function of shear stress showed clear similarities. This result supports the hypothesis that the flow dynamics of the CMF suspensions are those of flocs and not individual fibrils and that the shear thinning behavior

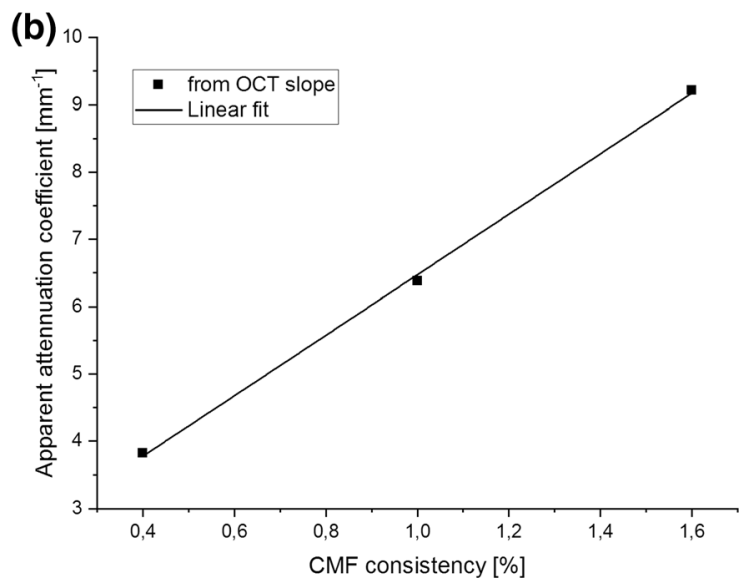

attenuation coefficients (the fit parameter $B$ ) as a function of the $\mathrm{CMF}$ consistency (the solid line is a linear fit to the data points) 
of CMF suspensions is closely related to decreasing floc size.

An apparent attenuation coefficient of the structural OCT signal was determined by fitting an exponential function with two variables (attenuation and intensity) to it. We determined an accurate linear relationship between the obtained apparent attenuation coefficients and the CMF consistencies.

Earlier studies have shown that OCT is an excellent tool for analyzing the flow dynamics of the CMF wall depletion layer. In this work, we demonstrated that OCT is quite useful also for analyzing the bulk properties of CMF suspensions, including viscosity, floc size, and consistency. The versatility of OCT makes it a multi-purpose tool not only for academic studies, but potentially also for industrial process and quality control.

Acknowledgments The experiments were carried out in a laboratory facility at the University of California, Davis, Department of Food Science and Technology. The authors greatly appreciate the collaboration with UC Davis, in particular with Professor Michael J. McCarthy and Professor Robert L. Powell. Additionally, J. Lauri would like to express his gratitude to Adjunct Professor Alexander V. Bykov for the insightful discussions on the OCT's signal formation. The work is part of the Academy of Finland's Flagship Programme under Project No. 318891 (Competence Center for Materials Bioeconomy, FinnCERES).

Funding Open access funding provided by VTT Technical Research Centre of Finland Ltd.

\section{Compliance with ethical standards}

Conflict of interest The authors declare no conflict of interest.

Open Access This article is licensed under a Creative Commons Attribution 4.0 International License, which permits use, sharing, adaptation, distribution and reproduction in any medium or format, as long as you give appropriate credit to the original author(s) and the source, provide a link to the Creative Commons licence, and indicate if changes were made. The images or other third party material in this article are included in the article's Creative Commons licence, unless indicated otherwise in a credit line to the material. If material is not included in the article's Creative Commons licence and your intended use is not permitted by statutory regulation or exceeds the permitted use, you will need to obtain permission directly from the copyright holder. To view a copy of this licence, visit http://creativecommons.org/licenses/by/4.0/.

\section{References}

Almasian M, Bosschaart N, van Leeuwen TG, Faber DJ (2015) Validation of quantitative attenuation and backscattering coefficient measurements by optical coherence tomography in the concentration-dependent and multiple scattering regime. J Biomed Opt 20:1-11. https://doi.org/10.1117/1. JBO.20.12.121314

Arola DF, Barrall GA, Powell RL, McCarthy KL, McCarthy MJ (1997) Use of nuclear magnetic resonance imaging as a viscometer for process monitoring. Chem Eng Sci 52:2049-2057. 2509(97)00033-X

Barnes HA, Hutton JF, Walters K (1989) An Introduction to Rheology. Elsevier, Amsterdam

Barnes HA (1995) A review of the slip (wall depletion) of polymer solutions, emulsions and particle suspensions in viscometers: its cause, character, and cure. J Non-Newton Fluid Mech 56:221-251. https://doi.org/10.1016/03770257(94)01282-M

Barnes HA (2000) Measuring the viscosity of large-particle (and flocculated) suspensions - a note on the necessary gap size of rotational viscometers. J Non-Newton Fluid Mech 94:213-217. https://doi.org/10.1016/S03770257(00)00162-2

Bounoua S, Lemaire E, Férec J, Ausias G, Kuzhir P (2016) Shear-thinning in concentrated rigid fiber suspensions: Aggregation induced by adhesive interactions. J Rheol 60:1279-1300. https://doi.org/10.1122/1.4965431

Brochard F, De Gennes PG (1992) Shear-dependent slippage at a polymer/solid interface. Langmuir 8:3033-3037. https:// doi.org/10.1021/1a00048a030

Chen Z, Milner TE, Dave D, Nelson JS (1997) Optical Doppler tomographic imaging of fluid flow velocity in highly scattering media. Opt Lett 22:64-66

Cheng G, Zhou M, Wei Y, Cheng F, Zhu P (2019) Comparison of mechanical reinforcement effects of cellulose nanocrystal, cellulose nanofiber, and microfibrillated cellulose in starch composites. Polym Compos 40:E365E372. https://doi.org/10.1002/pc. 24685

Coufort C, Dumas C, Bouyer D, Liné A (2008) Analysis of floc size distributions in a mixing tank. Chem Eng Process 47:287-294. https://doi.org/10.1016/j.cep.2007.01.009

Derakhshandeh B, Hatzikiriakos SG, Bennington CPJ (2010) Rheology of pulp suspensions using ultrasonic Doppler velocimetry. Rheol Acta 49:1127-1140. https://doi.org/10. 1007/s00397-010-0485-2

Desmaisons J, Boutonnet E, Rueff M, Dufresne A, Bras J (2017) A new quality index for benchmarking of different cellulose nanofibrils. Carbohydr Polym 174:318-329. https:// doi.org/10.1016/j.carbpol.2017.06.032

Dimic-Misic K, Gane PAC, Paltakari J (2013) Micro- and nanofibrillated cellulose as a rheology modifier additive in CMC-containing pigment-coating formulations. Ind Eng Chem Res 52:16066-16083. https://doi.org/10.1021/ ie 4028878

Drexler W, Fujimoto JG (2008) Optical Coherence Tomography-Technology and Applications. Springer, Berlin

Eriksen Ø, Kristin S, Gregersen $\varnothing$ (2008) The use of microfibrillated cellulose produced from kraft pulp as strength 
enhancer in TMP paper. Nord Pulp Pap Res J 23:299-304. https://doi.org/10.3183/npprj-2008-23-03-p299-304

Faber DJ, van der Meer FJ, Aalders MCG, van Leeuwen TG (2004) Quantitative measurement of attenuation coefficients of weakly scattering media using optical coherence tomography. Opt Express 12:4353-4365. https://doi.org/ 10.1364/OPEX.12.004353

Gong P, Almasian M, van Soest G, de Bruin D, van Leeuwen T, Sampson D, Faber D (2020) Parametric imaging of attenuation by optical coherence tomography: review of models, methods, and clinical translation. J Biomed Opt 25:1-34. https://doi.org/10.1117/1.JBO.25.4.040901

Haavisto S, Cardona MJ, Salmela J, Powell RL, McCarthy MJ, Kataja M, Koponen AI (2017) Experimental investigation of the flow dynamics and rheology of complex fluids in pipe flow by hybrid multi-scale velocimetry. Exp Fluids 58:158. https://doi.org/10.1007/s00348-017-2440-9

Haavisto S, Salmela J, Jäsberg A, Saarinen T, Karppinen A, Koponen A (2015) Rheological characterization of microfibrillated cellulose suspension using optical coherence tomography. Tappi J 14:291-302

Haavisto S, Lille M, Liukkonen J, Jäsberg A, Koponen A, Salmela J (2011) Laboratory-scale pipe rheometry: a study of a microfibrillated cellulose suspension. Proc Papercon 2011:357-370

Hillman TR, Adie SG, Seemann V, Armstrong JJ, Jacques SL, Sampson DD (2006) Correlation of static speckle with sample properties in optical coherence tomography. Opt Lett 31:190-192. https://doi.org/10.1364/OL.31.000190

Honorato C, Kumar V, Liu J, Koivula H, Xu C, Toivakka M (2015) Transparent nanocellulose-pigment composite films. J Mater Sci 50:7343-7352. https://doi.org/10.1007/ s10853-015-9291-7

Hourani MJ (1988a) Fiber flocculation in pulp suspension flow: Part 2. Experimental results . Tappi J 71:186-189

Hourani MJ (1988b) Fiber flocculation in pulp suspension: Part 1. Theoretical model . Tappi J 71:115-118

Huang D, Swanson EA, Lin CP, Schuman JS, Stinson WG, Chang W, Hee MR, Flotte T, Gregory K, Puliafito CA, Fujimoto JG (1991) Optical coherence tomography. Science 254:1178-1181. https://doi.org/10.1126/science. 1957169

Hubbe M, Tayeb P, Joyce M, Tyagi P, Kehoe M, Dimic-Misic K, Pal L (2017) Rheology of nanocellulose-rich aqueous suspensions: a review. BioResources 12:9556-9661

Iotti M, Gregersen ØW, Moe S, Lenes M (2011) Rheological studies of microfibrillar cellulose water dispersions. J Polym Environ 19:137-145. https://doi.org/10.1007/ s10924-010-0248-2

Kalkman J, Bykov AV, Faber DJ, van Leeuwen TG (2010) Multiple and dependent scattering effects in Doppler optical coherence tomography. Opt Express 18:3883-3892. https://doi.org/10.1364/OE.18.003883

Karppinen A, Saarinen T, Salmela J, Laukkanen A, Nuopponen M, Seppälä J (2012) Flocculation of microfibrillated cellulose in shear flow. Cellulose 19:1807-1819. https://doi. org/10.1007/s10570-012-9766-5

Kataja M, Haavisto S, Salmela J, Lehto R, Koponen A (2017) Characterization of micro-fibrillated cellulose fiber suspension flow using multi scale velocity profile measurements. Nord Pulp Pap Res J 32:473-482. https:// doi.org/10.3183/npprj-2017-32-03-p473-482

Kholodnykh AI, Petrova IY, Motamedi M, Esenaliev RO (2003) Accurate measurement of total attenuation coefficient of thin tissue with optical coherence tomography. IEEE J Sel Top Quantum Electron 9:210-221. https://doi.org/10. 1109/JSTQE.2003.814194

Kim J, Lee D, Lee Y, Chen W, Lee S (2019) Nanocellulose for energy storage systems: beyond the limits of synthetic materials. Adv Mater 31:1804826. https://doi.org/10.1002/ adma.201804826

Klemm D, Kramer F, Moritz S, Lindström T, Ankerfors M, Gray D, Dorris A (2011) Nanocelluloses: A new family of nature-based materials. Angew Chem Int Ed 50:5438-5466. https://doi.org/10.1002/anie.201001273

Koponen A (2020) The effect of consistency on the shear rheology of aqueous suspensions of cellulose micro- and nanofibrils: a review. Cellulose 27:1879-1897. https://doi. org/10.1007/s10570-019-02908-w

Koponen A, Haavisto S, Salmela J, Markku K (2019) Slip flow and wall depletion layer of microfibrillated cellulose suspensions in a pipe flow. Ann Trans Nord Soc Rheol 27:13-20

Koponen A, Lauri J, Haavisto S, Fabritius T (2018) Rheological and flocculation analysis of microfibrillated cellulose suspension using optical coherence tomography. Appl Sci 8:1. https://doi.org/10.3390/app8050755

Kose R, Yamaguchi K, Okayama T (2015) Influence of addition of fine cellulose fibers on physical properties and structure of paper. Fiber 71:85-90. https://doi.org/10.2115/fiber.71. 85

Kumar V, Nazari B, Bousfield DW, Toivakka M (2016) Rheology of microfibrillated cellulose suspensions in pressuredriven flow. Appl Rheol 26:43534. https://doi.org/10.3933/ ApplRheol-26-43534

Lasseuguette E, Roux D, Nishiyama Y (2008) Rheological properties of microfibrillar suspension of TEMPO-oxidized pulp. Cellulose 15:425-433. https://doi.org/10.1007/ s10570-007-9184-2

Lauri J, Koponen A, Haavisto S, Czajkowski J, Fabritius T (2017) Analysis of rheology and wall depletion of microfibrillated cellulose suspension using optical coherence tomography. Cellulose 24:4715-4728. https://doi.org/ 10.1007/s10570-017-1493-5

Lavoine N, Desloges I, Dufresne A, Bras J (2012) Microfibrillated cellulose - its barrier properties and applications in cellulosic materials: a review. Carbohydr Polym 90:735-764. https://doi.org/10.1016/j.carbpol.2012.05. 026

Leitgeb R, Hitzenberger C, Fercher A (2003) Performance of fourier domain vs. time domain optical coherence tomography. Opt Express 11:889-894. https://doi.org/10.1364/ OE.11.000889

Li M, Wu Q, Song K, Qing Y, Wu Y (2015) Cellulose nanoparticles as modifiers for rheology and fluid loss in bentonite water-based fluids. ACS Appl Mater Interfaces 7:5006-5016. https://doi.org/10.1021/acsami.5b00498

Liao J, Pham KA, Breedveld V (2020) Rheological characterization and modeling of cellulose nanocrystal and TEMPOoxidized cellulose nanofibril suspensions. Cellulose 
27:3741-3757. https://doi.org/10.1007/s10570-02003048-2

Lu J, Wang T, Drzal LT (2008) Preparation and properties of microfibrillated cellulose polyvinyl alcohol composite materials. Compos A Appl Sci Manuf 39:738-746. https:// doi.org/10.1016/j.compositesa.2008.02.003

Martoïa F, Perge C, Dumont PJJ, Orgéas L, Fardin MA, Manneville S, Belgacem MN (2015) Heterogeneous flow kinematics of cellulose nanofibril suspensions under shear. Soft Matter 11:4742-4755. https://doi.org/10.1039/ C5SM00530B

Mohtaschemi M, Dimic-Misic K, Puisto A, Korhonen M, Maloney T, Paltakari J, Alava MJ (2014a) Rheological characterization of fibrillated cellulose suspensions via bucket vane viscometer. Cellulose 21:1305-1312. https:// doi.org/10.1007/s10570-014-0235-1

Mohtaschemi M, Puisto A, Illa X, Alava MJ (2014b) Rheology dynamics of aggregating colloidal suspensions. Soft Matter 10:2971-2981. https://doi.org/10.1039/C3SM53082E

Mohtaschemi M, Sorvari A, Puisto A, Nuopponen M, Seppälä J, Alava MJ (2014c) The vane method and kinetic modeling: shear rheology of nanofibrillated cellulose suspensions. Cellulose 21:3913-3925. https://doi.org/10.1007/s10570014-0409-x

Moon RJ, Schueneman GT, Simonsen J (2016) Overview of cellulose nanomaterials, their capabilities and applications. JOM 68:2383-2394. https://doi.org/10.1007/s11837-0162018-7

Mykhaylyk OO, Warren NJ, Parnell AJ, Pfeifer G, Laeuger J (2016) Applications of shear-induced polarized light imaging (SIPLI) technique for mechano-optical rheology of polymers and soft matter materials. J Polym Sci Part B: Polym Phys 54:2151-2170. https://doi.org/10.1002/polb. 24111

Otsu N (1979) A threshold selection method from gray-level histograms. IEEE Trans Syst Man Cybern 9:62-66. https:// doi.org/10.1109/TSMC.1979.4310076

Naderi A, Lindström T (2015) Rheological measurements on nanofibrillated cellulose systems: a science in progress. In: Mondal MIH (ed) Cellulose and cellulose derivatives: synthesis, modification and applications. Nova Science Publishers, New York, pp 187-204

Nechyporchuk O, Belgacem MN, Bras J (2016) Production of cellulose nanofibrils: a review of recent advances. Ind Crops Prod 93:2-25. https://doi.org/10.1016/j.indcrop. 2016.02.016

Nechyporchuk O, Belgacem MN, Pignon F (2014) Rheological properties of micro-/nanofibrillated cellulose suspensions: Wall-slip and shear banding phenomena. Carbohydr Polym 112:432-439. https://doi.org/10.1016/j.carbpol.2014.05. 092

Pääkkönen T, Dimic-Misic K, Orelma H, Pönni R, Vuorinen T, Maloney T (2016) Effect of xylan in hardwood pulp on the reaction rate of TEMPO-mediated oxidation and the rheology of the final nanofibrillated cellulose gel. Cellulose 23:277-293. https://doi.org/10.1007/s10570-015-0824-7

Powell RL (2008) Experimental techniques for multiphase flows. Phys Fluids 20:040605. https://doi.org/10.1063/1. 2911023

Puisto A, Illa X, Mohtaschemi M, Alava MJ (2012a) Modeling the viscosity and aggregation of suspensions of highly anisotropic nanoparticles. Eur Phys J E 35:6. https://doi. org/10.1140/epje/i2012-12006-1

Puisto A, Illa X, Mohtaschemi M, Alava M (2012b) Modeling the rheology of nanocellulose suspensions. Nord Pulp Pap Res J 27:277-281. https://doi.org/10.3183/npprj-2012-2702-p277-281

Raj P, Blanco A, de la Fuente E, Batchelor W, Negro C, Garnier G (2017) Microfibrilated cellulose as a model for soft colloid flocculation with polyelectrolytes. Colloids Surf Physicochem Eng Aspects 516:325-335. https://doi.org/ 10.1016/j.colsurfa.2016.12.055

Rofe CJ, de Vargas L, Perez-González J, Lambert RK, Callaghan PT (1996) Nuclear magnetic resonance imaging of apparent slip effects in xanthan solutions. J Rheol 40:1115-1128. https://doi.org/10.1122/1.550775

Saarikoski E, Saarinen T, Salmela J, Seppälä J (2012) Flocculated flow of microfibrillated cellulose water suspensions: an imaging approach for characterisation of rheological behaviour. Cellulose 19:647-659. https://doi.org/10.1007/ s10570-012-9661-0

Saarinen T, Haavisto S, Sorvari A, Salmela J, Seppälä J (2014) The effect of wall depletion on the rheology of microfibrillated cellulose water suspensions by optical coherence tomography. Cellulose 21:1261-1275. https://doi.org/10. 1007/s10570-014-0187-5

Schenker M, Schoelkopf J, Gane P, Mangin P (2019) Rheology of microfibrillated cellulose (MFC) suspensions: influence of the degree of fibrillation and residual fibre content on flow and viscoelastic properties. Cellulose 26:845-860. https://doi.org/10.1007/s10570-018-2117-4

Schenker M, Schoelkopf J, Gane P, Mangin P (2018) Influence of shear rheometer measurement systems on the rheological properties of microfibrillated cellulose (MFC) suspensions. Cellulose 25:961-976. https://doi.org/10.1007/ s10570-017-1642-x

Schmitt JM, Knüttel A, Bonner RF (1993) Measurement of optical properties of biological tissues by low-coherence reflectometry. Appl Opt 32:6032-6042. https://doi.org/10. 1364/AO.32.006032

Sharma PR, Sharma SK, Lindström T, Hsiao BS (2020) Nanocellulose-enabled membranes for water purification: Perspectives. Adv Sustain Syst 4:1900114. https://doi.org/ 10.1002/adsu.201900114

Shin HJ, Son M, Lee G (2015) Stochastic flocculation model for cohesive sediment suspended in water. Water 7:2527-2541. https://doi.org/10.3390/w7052527

Smithies DJ, Lindmo T, Chen Z, Nelson JS, Milner TE (1998) Signal attenuation and localization in optical coherence tomography studied by Monte Carlo simulation. Phys Med Biol 43:3025-3044. https://doi.org/10.1088/0031-9155/ 43/10/024

Sugita M, Weatherbee A, Bizheva K, Popov I, Vitkin A (2016) Analysis of scattering statistics and governing distribution functions in optical coherence tomography. Biomed Opt Express 7:2551-2564. https://doi.org/10.1364/BOE.7. 002551

Takeda Y (2012) Ultrasonic Doppler velocity profiler for fluid flow. Springer, Berlin

Tatsumi D, Ishioka S, Matsumoto T (2002) Effect of fiber concentration and axial ratio on the rheological properties 
of cellulose fiber suspensions. Nihon Reoroji Gakkaishi 30:27-32. https://doi.org/10.1678/rheology.30.27

Thrane L, Yura HT, Andersen PE (2000) Analysis of optical coherence tomography systems based on the extended Huygens-Fresnel principle. J Opt Soc Am A 17:484-490. https://doi.org/10.1364/JOSAA.17.000484

Turpeinen T, Jäsberg A, Haavisto S, Liukkonen J, Salmela J, Koponen AI (2020) Pipe rheology of microfibrillated cellulose suspensions. Cellulose 27:141-156. https://doi.org/ 10.1007/s10570-019-02784-4

Vadodaria SS, Onyianta AJ, Sun D (2018) High-shear rate rheometry of micro-nanofibrillated cellulose (CMF/CNF) suspensions using rotational rheometer. Cellulose 25:5535-5552. https://doi.org/10.1007/s10570-018-19634

Varanasi S, He R, Batchelor W (2013) Estimation of cellulose nanofibre aspect ratio from measurements of fibre suspension gel point. Cellulose 20:1885-1896. https://doi.org/ 10.1007/s10570-013-9972-9

Vermeer KA, Mo J, Weda JJA, Lemij HG, de Boer JF (2013) Depth-resolved model-based reconstruction of attenuation coefficients in optical coherence tomography. Biomed Opt Express 5:322-337. https://doi.org/10.1364/BOE.5. 000322
Wang Y, Wang RK (2011) Measurement of particle concentration in flow by statistical analyses of optical coherence tomography signals. Opt Lett 36:2143-2145. https://doi. org/10.1364/OL.36.002143

Wunderlich T, Brunn PO (1999) Ultrasound pulse Doppler method as a viscometer for process monitoring. Flow Meas Instrum 10:201-205. https://doi.org/10.1016/S09555986(99)00016-3

Xia S, Huang Y, Peng S, Wu Y, Tan X (2017) Robust phase unwrapping for phase images in Fourier domain Doppler optical coherence tomography. J Biomed Opt 22:1-8. https://doi.org/10.1117/1.JBO.22.3.036014

Yadlowsky MJ, Schmitt JM, Bonner RF (1995) Multiple scattering in optical coherence microscopy. Appl Opt 34:5699-5707

Yun SH, Tearney GJ, de Boer JF, Bouma BE (2004) Motion artifacts in optical coherence tomography with frequencydomain ranging. Opt Express 12:2977-2998. https://doi. org/10.1364/OPEX.12.002977

Publisher's Note Springer Nature remains neutral with regard to jurisdictional claims in published maps and institutional affiliations. 